\title{
We Asked the Experts: Autotransfusion for the Provision of Blood in Lower-and-Middle-Income Countries
}

\author{
Timothy Craig Hardcastle ${ }^{1}$ (D)
}

Accepted: 15 March 2021/Published online: 29 March 2021

(C) Société Internationale de Chirurgie 2021

Space travel is often touted as the pinnacle of human progress, with the current missions to Mars an example thereof [1]. For those living in Lower-and-Middle-Income Countries (LMICs), this is but a pipe-dream. They face the daily mission of survival, with much less resources than higher-income countries. The level of trauma is also well known to be higher in these countries, with the additional burden of a restricted access to safe and affordable blood transfusion [2].

Blood safety is a priority for the various providers of blood products and the risk of infectious transmission is a reality, however much reduced in many parts of the world due to modern technology [3]. On top of these challenges are the high rates of retroviral disease and malaria in many parts of the world, where many of the LMICs are located [3]. All of these factors combined with poor fiscal resources and the need to pay for healthcare in LMICs leads to needless death from hemorrhage. For this reason, it is important for LMICs to establish cost-effective, yet efficient solutions to the shortage of blood products. One such solution is the reinfusion of the patient's own blood recovered during emergency department resuscitation or during surgery $[4,5]$. Emergency autotransfusion is nothing novel, having been first described in the 1800's [4].

A recent systematic review of blood transfusion strategies and options in LMICs found only one randomized trial and a number of cohort studies around blood transfusion in

Timothy Craig Hardcastle

hardcastle@ukzn.ac.za

1 Inkosi Albert Luthuli Central Hospital and University of KwaZulu-Natal, 800 Vusi Mzimela Rd, Mayville, Durban, ZA, South Africa trauma in LMICs. Only the randomised trial (originally published in this journal in 2006) addressed the possibility of autotransfusion, but the review also highlighted the low number of trauma cases with access to blood products [2]. Autotransfusion is not a new concept; however, the practicalities and costs have often precluded the use of this option to more financially robust countries. A Cochrane review on autotransfusion in trauma found the same randomized study as the only one to be included in the review and concluded that the role of autotransfusion was still equivocal [6].

The challenge is therefore to identify low-cost, safe options that are simple to use for LMICs. The most common systems used in high-income settings include the cellsaver devices (costly) and for thoracic blood the various models of three-chamber chest drain devices (but cannot be used for contaminated blood). One low-cost option is to utilise simple underwater drainage bottles connected to a chest tube to collect blood from an acute hemothorax and then salvage the blood for re-infusion via an empty saline bag. The only prerequisite is using normal saline in the chest drain bottle rather than sterile water.

Another option is a recently designed mobile waterless chest-drain device, that was originally developed and tested in a small, randomized trial for drainage of hemo- and pneumothorax [7]. This device was subsequently modified after clinical experience and advice to the manufacturer to incorporate a larger fluid chamber, plus an exit port to enable connection of a blood-giving set for autotransfusion. Up to $1200 \mathrm{ml}$ can be delivered by simply changing the device connected to the patient for an empty one and then hanging the full chamber above the patient to infuse the patient's own blood. The adverse effect risk is low and the patient will not receive any unexpected infection that they did not already possess. (See Fig. 1) [8]. Similar devices 


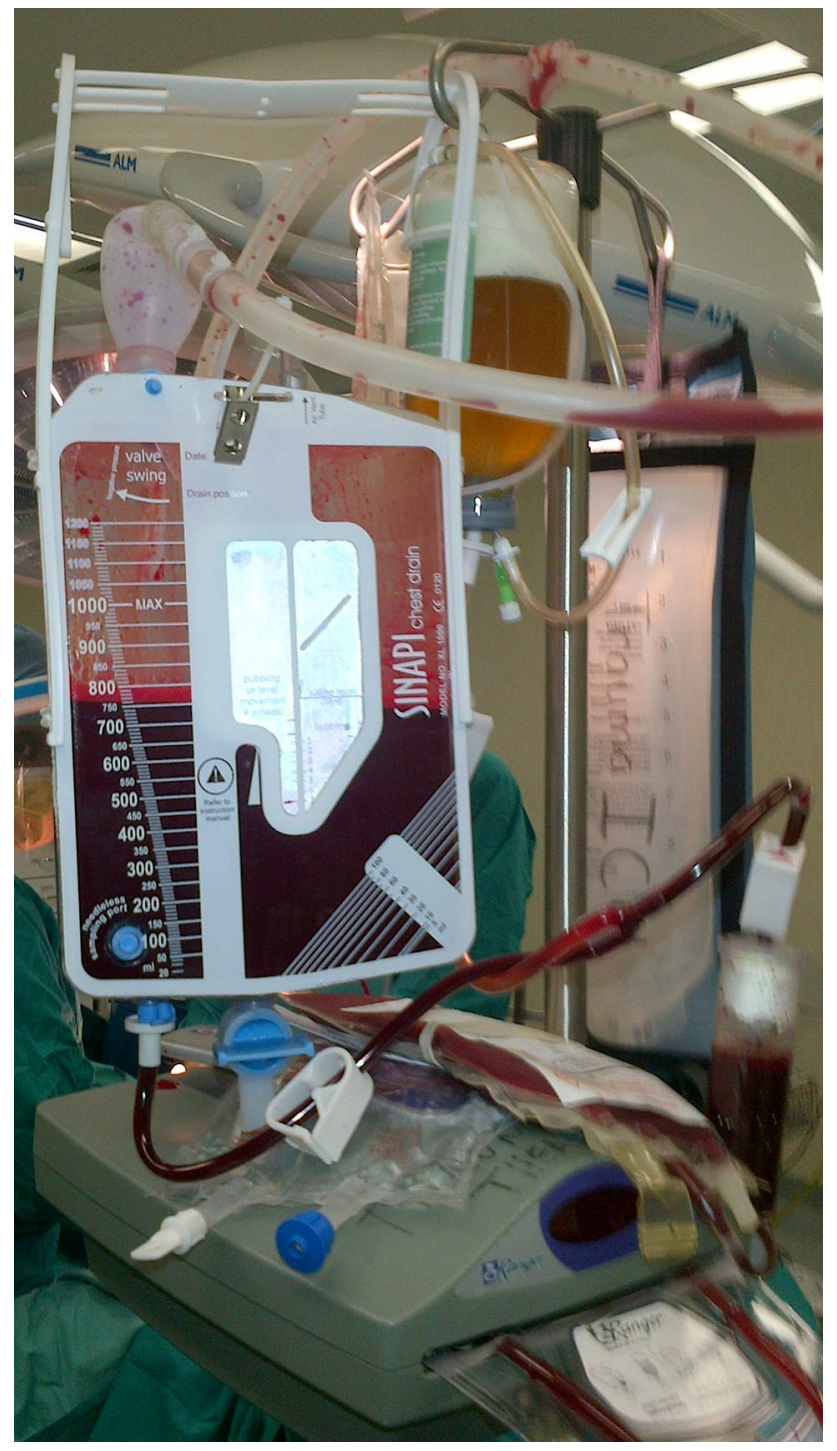

Fig. 1 Autotransfusion using the device designed in an LMIC for cheap but effective blood salvage

have been designed and tested in the military setting recently; however, these would appear to be more costly [9].

Further techniques for the use of blood salvaged from abdominal trauma include the use of blood from splenic or hepatic trauma are mentioned. Clinical uptake of these low-cost practical options are poor, however, as highlighted in a recent survey report in this very journal [10]. Sjöholm and colleagues reported that, despite simple experience-based techniques being available, with anecdotal evidence showing anticoagulants were not required for chest-blood, clinicians were fearful of using such techniques and it was considered a "last-resort" action. Filtering of blood through gauze layers was proposed as a cost-effective salvage option. Despite this, lack of practitioner familiarity with autotransfusion and lack of low-cost devices were cited as reasons for the low uptake by those working in austere circumstances.

The device referred to earlier, designed and produced in an LMIC, may just meet the needs for a low-cost, easy-touse, practical device [8]. It costs less than $\$ 15$, can be used to drain blood from a chest or to secondarily salvage blood from surgical suctions devices and can then be used to directly transfuse the blood back to the patient.

Since this is a safe option with low risk of adverse events it is time for all LMICs to actively work toward ensuring accessibility to such low-cost devices and thus enable more severe-trauma patients to get blood products with the expectation of an increase in survival, given the challenges of bank-blood availability and safety.

\section{Declarations}

Conflict of interest Invited expert opinion. I was involved in original testing of the Sinapi device and modification for the use of the device for autotransfusion, however I have no financial interest in the manufacturer or distributor. I am an Associate Editor of World Journal of Surgery.

\section{References}

1. NASA-Science. MARS 2020 Mission -Perseverance Rover. https://mars.nasa.gov/mars2020/. Accessed on 03/03/2021.

2. Yang L, Slate-Romano J, Marqués CG et al (2020) Evaluation of blood product transfusion therapies in acute injury care in lowand middle-income countries: a systematic review. Injury 51:1468-1476. https://doi.org/10.1016/j.injury.2020.05.007

3. Hardcastle TC (2006) Complications of massive transfusion in trauma patients. ISBT Sci Ser 1(1):180-184

4. Young GP, Purcell TB (1983) Emergency autotransfusion. Ann Emerg Med 12:180-186

5. Bowley DM, Barker P, Boffard KD (2006) Intraoperative blood salvage in penetrating abdominal trauma: a randomised, controlled trial. World J Surg 30:1074-1080. https://doi.org/10.1007/ s00268-005-0466-2

6. Li J, Sun SL, Tian JH, et al. (2015) Cell salvage in emergency trauma surgery. Cochrane Database of Systematic Reviews. Issue 1. Art. No.: CD007379. https://doi.org/10.1002/2F14651858. CD007379.pub2

7. Cooper C, Hardcastle TC (2006) Xpand chest drain: assessing equivalence to current standard therapy-a randomised controlled trial. S Afr J Surg 44(4):131-135

8. Biomedical S, De Villiers C (2016) Autologous blood transfusion: Sinapi chest drain XL1000 \& XL1000s models. Brochure for medical staff, Sinapi Biomedical, Stellenbosch, South Africa, July 
9. Gourlay T, Simpson C, Robertson CA (2018) Development of a portable blood salvage and autotransfusion technology to enhance survivability of personnel requiring major medical interventions in austere or military environments. J R Army Med Corps 164:96-102. https://doi.org/10.1136/jramc-2017-000789

10. Sjöholm A, Ălgå A, Von Shreeb J (2020) A last resort when there is no blood: experiences and perceptions of intraoperative autotransfusion among medical doctors deployed to resourcelimited settings. World J Surg 44:4052-4059. https://doi.org/10. 1007/s00268-020-05749-y

Publisher's Note Springer Nature remains neutral with regard to jurisdictional claims in published maps and institutional affiliations. 